\title{
Reforma do Currículo da Faculdade de Direito
}

Carlos Alberto Bittar

Professor-Adjunto de Direito Civil da Faculdade de Direito da USP

\begin{abstract}
RESUMO: A análise da posição atual da Universidade no contexto geral da sociedade mostra a necessidade de integração de seus mecanismos e de suas produções à realidade presente, frente ao flagrante descompasso existente. Reflexo dessa situação encontra-se no currículo da Faculdade de Direito, a qual, inobstante venha atuando condignamente no cumprimento de suas finalidades, ressente-se de ajuste em sua textura proy'ramática, em especial quanto ao ciclo de especialização. Deve-se implantar sistema que, coerente com a realidade do momento, prepare o profissional para as diferentes habilitaçōes da carreira, distribuindo-se as matérias em consonância com essas áreas de ação e com a inserçāo de disciplinas integrativas, de caráter não jurídico, como de economia, de contabilidade aplicada, de computaçāo e outras. Nesse sentido, a proposta que oferecemos, voltada exatamente para a melhor integração do profissional de Direito ao mundo fático atual.
\end{abstract}

\section{Termos mais significativos}

Universidade - Integração à sociedade - Revisão de currículo - Inserção de matérias integrativas - Especialização por área de atuação do profissional.

\section{A Universidade e sua significação no contexto social.}

\subsection{Introdução: a indissociabilidade entre a questão curricular e a textura geral da Universidade.}

De enorme complexidade mostra-se o tema da análise do currículo de uma Faculdade, em especial de Direito, e, muito mais ainda, quanto esta é a do Largo de São Francisco, exatamente porque é impossível dissociar-se esse estudo de prévias discussões de caráter geral, envolvendo, de um lado, a própria textura da Universidade e sua situação atual e, de outro, a posição específica da $\mathrm{Fa}$ culdade em questão que, aliás, pela riqueza de suas peculiaridades, confere colorido especial à pesquisa.

Assim afloram, dentre outras, questões como a da definição dos objetivos da Universidade e sua integração ao contexto social; a de sua estrutura presente e respectiva adaptaçāo a exigências do momento; a da situação específica da unidade em exame; a da lógica da esquematização curricular vigente e seus resultados. 
Não é sem razão que RODERICK A. MACDONALD, ao discorrer sobre o desenvolvimento dos currículos das Faculdades de Direito em seu país, assinalava que "discussions of the law-school curriculum typically highlight new courses, new methodologies, and new programs", realçando que "few exarnine curricular reform itself' ("Curricular development in the 1980s: 'a perspective', in 'Journal of Legal Education' ", 1982, v. 32, no 4, p. 571 e ss.).

E isso é assim porque a eleição de um currículo pressupõe: a prévia definição de metas e de objetivos gerais e específicos; análise da realidade presente e em suas projeções para o futuro; estudo das condicionantes; e, por fim, adoção de fórmulas compatíveis, sempre em funçāo do potencial humano e material existentes na Universidade e, em particular, na unidade em estudo.

Envolve, assim, no debate em causa, o eterno problema da crise na Universidade, decantado, ao longo do tempo, aqui e alhures, e cercado, como sempre, de indefectíveis conotações políticas, econômicas e sociais, e impregnado da indisfarsável subjetividade do analista, exigindo-lhe, antes do exame e da definição da esquematização curricular, prévia tomada de posição quanto aos temas enunciados.

Por isso é que dividimos o presente estudo em três partes, a primeira reservada à análise da Universidade em si; a segunda à das Faculdades de Direito e, a terceira, à dos respectivos currículos, em especial, o de nossa Faculdade, abordando, com os limites que os trabalhos do gênero impōem, os problemas mais gerais para deter-nos depois sobre a questão visada. Não nos aprofundamos, outrossim, em debate sobre metodologia, eis que será objeto de estudo específico na Comissão de Ensino.

Propomos, em seu contexto, a título de colaboração, algumas sugestōes que nos parecem pertinentes, a nível de Universidade e de Faculdade, esperando possam contribuir para o desate de problemas que enfrenta o mundo acadêmico no estágio presente.

\subsection{A Universidade nos dias atuais e seus objetivos.}

Ninguém contesta a extraordinária contribuição da Universidade à sociedade, sobre a qual vem, ao longo dos tempos, graças à integração ensino - pesquisa - serviços, exercendo enorme influência, nas áreas da informação, formação profissional, produção técnica e prestação de serviços, como tivemos oportunidade de acentuar em conferência proferida nesta Faculdade, no Seminário “O ensino universitário e o Direito de Autor”, promovido, em 1984, pelo Instituto Interamericano de Direito de Autor (publicada, com o título "Novas técnicas de comunicação no âmbito universitário e seus reflexos na comunidade", in “Revista de Informaçāo Legislativa", 1985, no 86, p. 332). 
Indubitáveis são, também, as profundas modificações ocorridas, nos últimos tempos, na vida comum e no mundo negocial, na prática, nas ciências e nas técnicas, a suscitar novas exigências e a requerer novas posturas de todos os seres responsáveis.

Vivemos a era da utilizaçāo do átomo, da tecnologia sofisticada, das comunicações por satélites e das viagens espaciais, com desafios cada vez mais agudos à inteligência e à sensibilidade humanas. Mas assistimos também a grandes choques ideológicos e políticos, a indagações sobre o futuro do homem e seu dimensionamento na Terra, a especulações sobre o equilíbrio nas relações entre as diferentes nações e grupos sociais.

Questiona-se, frente às novas realidades, a posição da Universidade para efeito de saber-se, de início, se vem contribuindo, efetivamente, para a sociedade e, depois, se está preparada para os desafios do porvir.

Nesse contexto, indaga-se, desde a sua estruturação orgânica à sua forma de atuação e de seus objetivos a seus programas, qual a postura compatível da Universidade no presente momento, frente às modificações havidas na sociedade e às perspectivas para o futuro.

Não se cura, em verdade, de discussão nova ou recente, eis que sempre se cogitou e sempre se cogitará desse interrelacionamento, pois a problemática em causa se vincula à eterna questão da busca de valores e de meios considerados adequados para a condução da vida nas respectivas comunidades. Mas, trata-se, seguramente, de debate que ora assume acendrado interesse frente ao constante ingresso de condicionantes novas, que põem o homem diante de situaçōes nunca antes enfrentadas, em especial a do exacerbado tecnicismo que vem sufocando valores mais altos de sua própria essencialidade.

Em um primeiro momento, pode-se dizer que a Universidade vein cumprindo, de um modo geral, os objetivos que se lhe reconhecem como básicos, sintetizados por MOACYR EXPEDITO M. VAZ GUIMARÃES, em 1980, em palestra proferida no Conselho Técnico de Economia, Sociologia e Política da Federação do Comércio do Estado de São Paulo, nos de: "conservação e transmissão da cultura através da docência"; "busca de novos conhecimentos através da reflexāo e da pesquisa"; e "extensão de serviço à comunidade". ("Universidade e comunidade: integraçāo inadiável", in "Problemas Brasileiros", 1980, n- 193, p. 8).

Exerce, assim, a Universidade as diferentes missões que lhe cabem, no dizer de PERKINS, a saber: a de aquisição de conhecimento (missão de investigação), a de transmissões de conhecimento (missão de ensinamento); e a de aplicação do conhecimento (missão de serviço público). 
Mas, de outro lado, coerente com o espírito prático dominante em diferentes segmentos da sociedade atual, vem a Universidade gerando e introduzindo no mundo fático novas técnicas, novos produtos e novos instrumentos de utilização científica, industrial e comercial, conhecendo-se, entre nós, inúmeros e frutíferos exemplos do denominado "pragmatismo universitário" no domínio da tecnologia, realizado nas várias Universidades oficiais do país ("Brasil Universidade 78", Suplemento especial da Revista "Manchete", no 1369, de 15.7.78).

\subsection{Breve retrospecto histórico.}

Com isso, pode-se verificar que se distancia, em muito, da concepção com que veio à lume na Antiguidade clássica, em que, nascida com objetivos puramente intelectuais, nos colóquios filosóficos mantidos nos jardins de "Academus" (donde o nosso "Academia"), tinha preocupação exclusivamente teórica.

Como instituição regular de ensino remonta ao século $X$, cunhando-se, no século XII, com um caráter teórico, sob inspiração do modelo canônico, mas recebendo, também, influência do poder político em sua atuação.

O ecletismo medieval da instituição - que assistiu, com o rompimento dos laços originais, primeiro a uma internacionalização das pesquisas, e, depois, à constituição de universidade nacionais - persistiu até a Revolução Industrial.

Com a introdução das máquinas no processo de produção, surgiu a preocupação de formação profissional frente às novas atividades que se foram revelando. A especialização passou a dominar a Universidade, que estendeu a sua atuação ao aprendizado de profissões, à pesquisa, à produção e à prestação de serviços.

Modernamente, utilizando-se das técnicas de comunicação postas à sua disposição e, por sua vez, formando novos valores humanos e gerando aparatos úteis à sociedade, a Universidade transformou-se, como anotamos no referido trabalho, "em centro difusor de cultura, ciência, arte e técnica a serviço da comunidade geral"(p. 334).

\subsection{A crise da instituiçāo: a dissociaçāo da realidade.}

Mas, de outro lado, evidente é a crise que experimenta a instituição na presente quadra, relacionada, aliás, à própria crise de valores por que atravessa a sociedade.

Acastelada sob estrutura distanciada da realidade, seja em termos de filòsofia de ação, seja em esquematização de poder, seja em recrutamento, em remuneração e em ascensão profissional de seus colaboradores, seja em existên- 
cia e em aproveitamento de aparato técnico disponível; a Universidade de nossos dias encontra-se defasada frente à dinâmica de uma sociedade inquieta e cambiante.

Essa ausência de sinergismo concentra-se internamente, como tem sido apontado: no plano da definição e da distribuição do poder, ainda vinculada, na área pública, à vontade dos governantes, fato que confere relatividade à sua autonomia; na excessiva burocratização de sua estrutura e na complexa esquematização de cargos e de funções; em política salarial absolutamente inadequada e desestimuladora; em certos desajustes na carreira docente e na posturado alunato, dentre outros fatores. Externamente, tem sido apontados: o distanciamento frente a exigências do mercado; o enclausuramento em suas posiçōes, que, dificilmente, alcançam a realidade; teorização em sua postura docente; a inadequação de currículos e a ausência ou inadequação de metodologia própria, dentre outros elementos.

Essas deficiências constam, como se sabe, de diferentes diagnósticos feitos sobre a Universidade atual - alguns adiante enunciados - tendo certas falhas sido enfatizadas recentemente por JOSÉ GOLDEMBERG, Reitor da Universidade de São Paulo, em seu discurso de posse ("Jornal da USP”, edição especial, sobre a nova administração, p. 2).

Razōes várias tem contribuido para esse estado de coisas, mas dentre elas avulta, nas oficiais, a questão da falta de verbas - apontada recentemente pelo mesmo Reitor - fato que impossibilita a realização de programas tendentes à sua adequação à evolução presente (V. editorial do jornal "O Estado de São Paulo", de 23.2 .86 , p. 3 , que se tem detido sobre a crise da Universidade, desde os editoriais de 1980 e 1984).

Chamamos a atenção, nesse ponto, para o incrível descompasso existente entre a remuneração de docentes e de funcionários da Universidade com a dos outros colaboradores do serviço público e de empresas privadas. Basta atentarse para o fato de que um professor concursado - e depois de enfrentar, com os sacrifícios conhecidos, os cursos de pós-graduação e concursos de defesa de tese e de ingresso em carreira - faz jus hoje a remuneração que, na empresa privada, se paga a auxiliares de escritório, com simples instrução secundária ... ou nem isso! ... Se levarmos em conta que, quando da criação do curso jurídico em $S$. Paulo e em Olinda, havia equivalência entre o ordenado do professor e o de desembargador, desoladora se torna a situaçāo, fato esse que obriga os protessores a desdobrar-se em outras atividades para manter nível de vida compatível com sua posição! ... Aliás a evasão de cérebros para a empresa privada - ou para outras atividades além da docência - é por demais conhecida e apregoada entre nós ... 
Com razão, pois, frisou recentemente PAULO NATHANAEL PEREIRA DE SOUZA que "uma política educacional que se esmerasse na construção dos prédios escolares, que se ocupasse de equipamentos sofisticados e que se aprofundasse em inovações curriculares e metodológicas, mas que se esquecesse do professor, estaria certamente fadada ao insucesso ("Professor e qualidade qualidade de ensino", in "O Estado de S. Paulo", de 13.2.86, p. 29).

As deficiências apontadas vem distanciando a Universidade da realidade da vida, desistimulando-se as atividades de pesquisas e de estudos aprofundados, fato que vem tolhendo a expansão de sua função de prestação de serviços, que, ao revés, no mundo presente, deveria ser a mais expressiva, frente às exigências do progresso material.

Retrai-se a produção científica, limitam-se as atividades universitárias à de transmissão de conhecimento e, com isso, aumenta progressivamente a defasagem apontada.

Urge imediata revisão dessa situação, criando-se mecanismos que sanem as falhas enunciadas, em especial quanto a dotação de verbas para pesquisas, a adoção de política salarial condizente com a dignidade das funçōes acadêmicas e a instituição de mecanismos que ampliem a área de serviços à comunidade.

\subsection{Necessidade de integraçāo à sociedade.}

Não é outro o discurso corrente entre os espíritos lúcidos.

Todos os que se tem voltado para os problemas acadêmicos apregoam, de forma altissonante, a urgente necessidade de integração da Universidade à sociedade, entendida como: participação na vida da nação, busca de soluções para os problemas existentes, e preparação de pessoal capacitado para os desafios que a vida atual oferece.

Salienta-se que deve estar atenta às necessidades do momento, interagindo com a sociedade, a fim de fornecer-lhe elementos tendentes a embasar um desenvolvimento coerente com o respeito aos valores que em seu seio alberga.

Nesse sentido, em Seminário realizado pela Comissão de Educação e Cultura da Câmara dos Deputados, em 1977, sobre o ensino superior, concluiuse que não pode a Universidade ater-se a atividades rotineira, devendo, também atuar em consonância com o momento, ajustando-se sempre às respectivas exigências, mas influindo sobre o meio, contribuindo para o aperfeiçoamento da vida em sociedade. 
Acentuou-se então que deve ser dotada de flexibilidade constante, reformulando-se sempre para poder cumprir, efetivamente, suas funçōes.

Por isso é que, ao cuidar do problema da integração da Universidade à sociedade, EXPEDITO VAZ GUIMARÃES assinalava que, para exercer função útil na comunidade, deveria a Universidade gozar de "autonomia didática, curricular, estrutural e legal", e ater-se "a exigência do mercado de trabalho, mas nāo exclusivamente em função disso".

Completou, ao depois, o seu pensamento, acentuando que deveria "estar de acordo com o seu tempo, ser capaz de manter diálogo com outras instituiçöes de cunho científico e promover o livre exercício da razäo".

No plano de ensino, deveria permitir a "coexistência entre uma orientação técnica e uma orientação humanística", na preservação e na proteção de seus valores. (o. cit., p. 9 e 10).

Nos debates travados à ocasião, restou clara a absoluta necessidade de contato estreito com a comunidade, nas palavras de PAULO GOMES ROMEO e LUIZ CINTRA DO PRADO, inclusive na proliferação de programas tendentes a conjugar-se com a empresa privada, como acentuou DORIVAL TEIXEIRA VIEIRA (Revista citada, pp. 11; 15 e 16).

É, realmente, com essa integração que se terá uma Universidade florescente, revigorada e útil à sociedade, correspondendo, pois, aos respectivos anseios, ao transmitir-lhe, via ensino - pesquisa - serviços, meios adequados para o seu aperfeiçoamento.

Acreditamos, no entanto, que, para vingar esse desiderato, qualquer proposta de reforma deve: rever a respectiva estrutura, valendo-se, na USP, inclusive de elementos constantes de anteprojeto elaborado na gestão anterior; acrescer-lhe as respectivas receitas; adotar imediata política salarial condizente com a realidade do mercado; incentivar a pesquisa e o estudo aprofundado; criar e por à disposição da sociedade novos serviços, tais como, cursos de extensāo e de aperfeiçoamento, institutos e centros de estudos e das pesquisas e outros.

Nesse sentido, estudos deveriam ser imediatamente desenvolvidos, pondose, a seguir, em prática, medidas positivas que atendam aos pontos enunciados, cumprindo, em nosso entender, que a Faculdade de Direito se empenhe nesse trabalho de reerguimento da instituição, dentro do espírito de participação que sempre a caracterizou.

Isso mais se faz sentir quando se tem presente que a evolução das Faculdades de Direito não foge à regra geral e, hoje, inseridas no contexto da Uni- 
versidade, sofrem diretamente - a par de razões peculiares - os reflexos da crise apontada.

2. As Faculdades de Direito e a orientaçāo predominante do ensino jurídico.

\subsection{O descompasso das Faculdades de Direito no contexto da sociedade.}

Com efeito, em seu processo de evolução, não tem as Faculdades de Direito, desde os primórdios de sua existência, fugido à regra quanto a seu posicionamento frente à sociedade.

De índole puramente teórica, no início, manifestavam como objetivo central o aperfeiçoamento intelectual, evoluindo, com o passar dos tempos, para uma postura mais pragmática, mas dentro dos limites de suas potencialidades, face, principalmente, ao predomínio das técnicas que caracteriza o estágio atual.

Com efeito, se a fundação da Universidade em Portugal, por exemplo, visava "a formaçāo maciça de intelectuais orgânicos" ("Universidade de Coimbra", opúsculo editado por sua Reitoria, em 1978, p.4), aparelhou-se depois, continuadamente, até, em nosso século, aproveitando-se do desenvolvimento tecnológico posto à sua disposição para vir a exercer as demais funçōes retroapontadas, inclusive de serviços à comunidade.

Entre nós, concebida a Universidade também como foco difusor de cultura, o progresso material do presente século lançou-a à busca de nova metas, notando-se, no entanto, certo distanciamento da realidade na atuação das $\mathrm{Fa}$ culdades de Direito.

Com efeito, se as demais Faculdades - especialmente das áreas técnicas - tem podido acompanhar e embasar esse desenvolvimento, as de Direito, até por sua própria natureza e por sua estruturação, sentiram mais fortemente esse impacto, assistindo-se, em nosso tempo, com o crescente predomínio do econômico sobre o social, um certo descompasso na posição dos juristas ante à realidade fática.

Exacerba, entre nós, essa situação o fenômeno da massificação do ensino superior, que alargou demasiadamente a oferta, com sensível prejuízo de qualidade, criando-se inúmeros cursos sem qualquer substância, a ponto de chegarse à proibição de instalação de novas Faculdades no país, depois de manifestaçōes candentes, inclusive de todas as entidades de classe, quanto à sofrível qualificação dos enormes contingentes de formandos. 
Verifica-se, pois, que a discussão sobre as Faculdades de Direito se reveste de nuances especiais, atingindo sua própria essencialidade, na medida em que interfere com a própria significação da instituição na presente quadra do desenvolvimento da sociedade.

\subsection{A crise do ensino jurídico: os debates quanto à orientaçāo geral e à composição do currículo.}

Debatem-se, com isso, os intelectuais entre extremos: humanismo ou pragmatismo; ensino jurídico ou sócio-jurídico; postura teórica ou prática?... E, inobstante os diferentes congressos, discussões, estudos, projetos e demais iniciativas tendentes ao equacionamento dessa situação, não se chegou, ainda, concretamente, a posições que, de fato, representem avanço significativo para reverter-se o processo!...

Por isso é que, em todos os países civilizados, patente é a crise nas Faculdades de Direito, pondo-se em choque, mesmo, já algum tempo, a sua própria identidade.

Esse problema tem merecido estudos e discussões por toda parte, geralmente com opiniōes que refletem o pessimismo - ou, mesmo, ceticismo - do analista quanto a resultados positivos a curto prazo.

Em congresso realizado na Universidade de Granada (conferências publicadas nos “Anales de la Catedra Francisco Suarez", 1980/81, n-s. 20/21, p.115 e segs.), especialistas de diferentes países europeus tiveram oportunidade de debruçar-se sobre o tema, discutindo seus diferentes aspectos.

Discorrendo sobre a formação dos juristas na Alemanha, assinalava WOLF PAUL, que se caracteriza curiosamente, "por determinadas contradicciones, que aun que claramente reconocidos y permanentemente lamentados, nunca pudieram ser efectivamente eliminadas", parecendo-lhe como "si tuvieram uma existencia incorregible." (Formácion del jurista entre teoría y praxis", p. 115).

Apontando depois os dois dilemas básicos das Faculdades, a saber, teoria ou "praxis" e ciência jurídica ou ciência social, acentuava que, no fundo, a questão se relacionava com a própria crise global do Estado.

Analisando, em seguida, as diferentes consequências dessa situação, propunha reforma, em que os elementos fundamentais deveriam ser: "enseñanza monofásica en el sentido de una integración homogénea de la practica jurídica 
en el plan de estudios; cientificidad del proceso educativo y de los exámenes; realización práctica como procedimento experimental".

Com isso, concluia, salientando acreditar "que la utopia, largo tiempo abstractamente mantenida, de una ciencia jurídica orientada a la praxis tiene la posibilidad de hacerse concreta". (p.133). (sobre a situaçāo da Alemanha, v. também GERHARD HANEY: "Formación jurídica y formación de los juristas en la República Democratica Alemana", o. cit., p. 135 e segs.).

Debatendo a questão na França, JACQUELINE GATI e JEAN-JACQUES GLEIZAL, depois de realçar o espírito conservador dos juristas, ressaltavam que "la enseñanza del Derecho ocupa un lugar destacado entre los temas prohibidos". (La enseñanza del Derecho y la formación de la capas dirigentes en Francia", o. cit., p,. 159 e segs.).

Acentuando que "no es posible imaginar una enseñanza del Derecho que no sea consciente de sus finalidades", criticavam o sistema atual (p.170 e segs.), em especial quanto ao caráter estritamente jurídico dos programas, que tem causado óbice à formação de pessoal administrativo exigido pelo país.

Em seguida, mostrando a prevalência dos técnicos nos dias atuais e formulando críticas à concepção vigente, concluiam que "lo que en adiante importa ho es tanto el Derecho como lenguaje específico que requiere un aprendizaje autónomo, sino el Derecho como instrumento de acción que necesita un saber práctico y especializado" (p. 180).

Por sua vez, VITTORIO FROSINI, iniciando seu discurso com o debate sobre as mudanças havidas na sociedade, evidenciava em especial, o tecnicismo e o gigantismo do Estado, salientando que "el licenciado en jurisprudencia no está preparado precisamente por sua formación especializada pero carente de apertura y flexibilidad". ("La Universidad desintegrada: la situación italiana", Rev. cit., p.228).

Entendia haver verdadeira desintegração da Universidade, em si e com respeito à sociedade em que está umbicada, porque, de um lado, "dentro de ella no actúa una integración de la vida intelectual comunitária" e, de outro, "sufre las consequencias de un fallido proceso de intercámbio vital de experiencia y de energias con el mundo exterior." (p. 232).

2.3. Necessidade de revisāo da orientaçāo: a conjugaçāo entre teoria e prática.

Autores não tem faltado em apregoar, mais concretamente, necessidade de revisão da orientação do curso, para ajustá-lo às novas realidades, acenando também com a imperatividade de estruturação curricular compatível. 
Assim, discutindo o tema em seu país, em 1966, expunha MARCELO CAETANO que a Faculdade de Direito tem como objetivo uma "formação jurídica básica", depois "complementada pela aprendizagem de uma profissāo".

Entendia que a "licenciatura é grau acadêmico" e nāo "título profissiònal", obtido, ao revés, em estágios e aprendizados próprios, concluindo por realçar a tendência de cursos complementares, de especialização ("A reforma dos estudos jurídicos em Portugal", in R.F. no 227, pp. 366 e 371).

Por sua vez, JOSÉ NABANTINO RAMOS, examinando diferentes problemas da vida univesitária, em trabalho sobre o estudo do Direito, apregoava a necessidade de um ensino voltado para a prática, inclusive em consonância com a respectiva legislação, "há, pois, que infundir ao ensino do Direito orientação profissional, de acordo, aliás, com a tendência dominante em outros países". ("O ensino do direito", in RT. 490/249).

No mesmo sentido, entendia, entre nós, CESARINO JUNIOR, em discurso proferido em 1966, que as Faculdades de Direito "não preparam seu alunos para a era tecnocrata em que devem operar", face, dentre outras razões, a sua "organizaçāo excessivamente tradicional em inteiro descompasso com as mudanças da civilização tecnológica".

Depois de comentar o avanço tecnológico e a ascenção do tecnocratas, salientava que o advogado também deveria ser um "técnico", mas sob ângulo diverso, pois the cabe "encarar todos os aspectos da vida".

Analisando, em seguida, o futuro do jurista na era tecnológica e depois de enunciar visōes apocalíticas de alguns escritores, concluia, no entanto, que "a sua univesidade e humanismo" "haverāo de mobilizar os espíritos na luta contra o materialismo e terminarāo por vencê-lo". ("o jurista na era tecnocrática", in "Revista da Faculdade de Direito", 1969, V. LXIV, p. 189, 201 e 204).

Também debates travados nos Estados Unidos da América do Norte - em que a crise é sentida e discutida - críticas não tem sido poupadas ao ensino jurídico.

Assim, DAVID M. HUNSAKER, ao escrever sobre a educação jurídica, afirmava que "must adapt to the needs of a rapidly changing, society", salientando que a necessidade básica, reconhecida por muitos, "is to develop in the student skills other than the ability to analyze cases critically". ("Law, humanism and communicacion: Suggestions for limited curricular reform", "Journal of Legal Education", 1980, v. 30, p. 417).

Pregava a criação de cursos por áreas de atuação do jurista ou mesmo extracurriculares, relacionados às diferentes funçōes comunicativas do advogado 
(como as de pesquisa, argumentação, consulta, negociação, etc.) (p.423), salientando que se consubstanciava em "realistic attempt to provide in the law school curriculum a basic core of skill courses which will tend to unify rather than fragment fruther, the proliferating specialty curriculum which has developed in recent years".

Acreditava, com isso, que "a curriculum package, such as the above, strikes the balance in a way which will have the most productive and least disruptive impact on modem legal education" (p. 434).

Já MALDONALD, depois de discutir a denominada "metafísica clássica" - com disciplinas compulsórias e opcionais - e a chamada "lógica artificial da "common law", enfatizava que "curricular reform is a continuing enterprise, beset by, tensions which are perennial", entendendo que a questão "reflect underlying problems which have been among the fundamental concerns of traditional speculative philosophy" (o. cit., p. 586).

E, consoante tem sido noticiado, o debate prossegue em várias Universidades do país, inclusive nas mais tradicionais, como a de Harvard, onde se vem pondo em choque a própria instituiçāo, cujo ensino tem sido "instrumento" de "injustiça social", para a corrente denominada "Critical Legal Studies". (Revista "Time" $18,11.85$, p. 39).

Outrossim, se, como se observa, se tem propugnado por uma orientação prática para o ensino, não tem faltado vozes que, ao revés, alertam para o excesso de pragmatismo que poderia comprometer a própria ciência jurídica.

Nesse sentido, MANUEL JESUS GARCIA GARRIDO, ao assinalar que objetivo básico do ensino jurídico é a "realización de la formación integral", advertia, em artigo sobre a reforma espanhola que se deveria evitar "excessivo conteúdo profissional", ditado pelo "utilitarismo da vida presente", ante ao pergio de "deixar de fazer ciência pela ciência" "La Universidad en la reforma educativa española", in "Revista da Faculdade de Direito", 1974, v. LXIX, fase 2, pp. 201 e 202).

Mas, concluia, com esperança, que "el espiritu y la tradición de nuestras viejas y nuevas Universidades superará los temporales del presente como ha superado los vaivenes de la História" (p. 203).

Em nosso entender, como sempre ocorre, in medio virtus, ou seja, não se pode conceber um ensino jurídico dirigido unicamente para a prática, nem se pode cogitar de uma postura puramente teórica no curso de Direito. Deve-se adotar orientação que concilie teoria e prática, formando o estudante, e, ao mesmo tempo, mostrando-lhe a aplicação dos princípios e das regras à vida co- 
mum, propondo-lhe a resolução de problemas, desenvolvendo o seu raciocínio, estimulando-o à pesquisa, aguçando-lhe o espírito crítico, fomentando a sua capacidade de argumentação, aperfeiçoando a sua redação.

Deve-se dar-lhe a conhecer as funçōes típicas do jurista na vida real, realizando-se pesquisas, trabalhos e estágios orientados; discussões de casos da vida real; resoluçōes de problemas, e sempre em razão de situações extraídas do cotidiano.

Com isso se sentirá o estudante integrado ao mundo em que vive, perceberá a presença do Direito na realidade fática e estará preparando-se para o posterior exercício das funçōes próprias de sua licenciatura.

Por isso é que ÁLVARO MELO FILHO enfatiza que "o estudo do Direito, no curso de graduação, visa a desenvolver o conhecimento básico da ciência jurídica paralelamente à formação profissional mediante ensino teóricoprático". ("Metodologia do ensino jurídico", Rio, Forense, 1979, p. 3).

Em nosso entender, é indispensável a presença do binômio formação-informação nos cursos jurídicos, ensinando-se princípios, regras e suas aplicaçōes - portanto, sob visão teório-prática - voltadas para o momento e, quanto possível, atentas às perspectivas do futuro.

Isso exige, como natural, preparação própria do professor e constante atualização, a par de postura participativa do aluno, além da adequação de pessoal e de material por parte da Faculdade.

Outrossim, algumas sugestões tem sido formuladas, mais objetivamente, para a adaptação do currículo jurídico às necessidades do mundo atual, à luz do espírito humanístico próprio da ciência do Direito, pugnando-se, de um lado, pela necessidade de conjugação entre teoria e prática em sua configuração e, de outro, pela integração à realidade social.

Assim, escrevendo sobre Universidades norte-americanas, OSCAR BARRETO FILHO apontava, em 1970, a flexibilidade dos currículos, que contavam com matérias obrigatórias (básicas) e opcionais (nos dois últimos anos).

Acentuava a existência de institutos de pesquisas na Universidade e o grande entrosamento entre eles e organismos públicos e particulares para a realização de pesquisas, com recursos de fontes diversas.

Mas, mesmo assim, já àquela época se acenava com a necessidade de mudança do sistema, para efeito de ajustar-se à realidade. 
$\mathrm{Na}$ conclusão, oferecia sugestōes para reformado ensino jurídico no Brasil, em que se destacavam: "reestruturaçāo do currículo, visando à flexibilidade e consequente ampliação de possibilidade de opção", e integração, nas Faculdades de Direito, de "matérias afins", "por meio de criaçāo de institutos ou cursos especializados" ("Novos Métodos do ensino do Direito - A experiência norte-americana", in “Revista Forense”, no 229, pp. 383, 387 e 389).

Por sua vez, CAIO TÁCITO, na mesma época, e em conferência no Conselho Técnico da Confederação Nacional do Comércio, reconhecendo as transformações jurídicas, econômicas e socias ocorridas entre nós, apontava uma “precariedade dos estudos jurídicos nas Faculdades", propugnando pela reforma do ensino jurídico, que se deveria "tomar integrado, tanto no sentido da maior comunicação entre o estudao das disciplinas jurídicas afins, como especialmente pela preparação em disciplinas para-jurídicas, colocadas no campo das ciências ecônomicas e sociais."

Lembrou, depois, a evolução ocorrida nos Estados Unidos do "case method" ao "problem method" e, finalmente, ao "interdisciplinary approach", preocupado com a "formaçäo do direito através de suas coordenadas sociais e econômicas".

Concluindo, propunha a adaptação das Faculdades de Direito à evolução havida, "sob pena de aceitar o invencível mergulho no descrédito de um sistema já superado e incompatível com as solicitaçōes do desenvolvimento nacional" ("O desafio do ensino do Direito", in "Revista Forense", no 233, pp. 329, 330 e 331).

\subsection{Necessidade de integração do currículo à realidade presente.}

De outro lado, deve o ensino ser impregnado do indispensável sentido humanístico, fazendo despertar no estudante a necessidade de defesa dos valores básicos do homem e da sociedade.

Nessa diretriz, ANDRÉ FRANCO MONTORO, depois de colocar como objetivo fundamental do ensino do Direito o de "formar juristas nacionais", enfatizava nele a necessidade de um caráter humanístico, a fim de que possa contribuir para uma sociedade mais justa ("Objetivos e método do ensino do Direito", in "Revista de Informação Legislativa", no 42, p. 63 e segs.).

Na mesma orientação, ADA PELLEGRINI GRINOVER, acentuava que o curso jurídico deve guardar o sentido humanístico, "para formar a consciência jurídica do bacharel" ("o advogado e a formação jurídica", in "Revista da Faculdade de Direito" in "Revista da Faculdade de Direito", 1978, v. LXXIII, p. 110). 
Com efeiţo, esse humanismo é de sua essência, até por definição, a nortear toda a estruturação e o desenvolvimento do curso, a fim de evitar-se, face ao excessivo tecnicismo, que venha a ocorrer, com as Faculdades de Direito, o criticado fenmeno da transformação, entre nós, de certas unidades de Universidades federais em verdadeiras "escolas profissionais de terceiro gran".

Deve-se, por fim, assentar a necessidade da integração do curso jurídico à realidade do país.

Defende-se a idéia de que, mediante a inserçāo de matérias afins no currículo das Faculdades, proporcionando ao estudante visão global da realidade em que atuará, estará mais apto a exercer suas funções, pois a excessiva carga de conhecimento específico o tem afastado de uma participação mais decisiva na condução, ou mesmo, na orientação, do desenvolvimento atual.

Quer-se evitar que o excessivo, ou o exclusivo, dimensionamento jurídico do currículo isole o bacharel das exigências da sociedade, com a consequente dissociação do jurista do mundo fático.

Assim, cumpre que o currículo seja moldado de forma a contemplar o estudo de outras áreas da ciência compatíveis com o Direito, como Economia, Finanças, Administração e outros.

Nesse diapasão, a inserção dessas matérias vem sendo feita nos últimos semestres do curso, como estudos complementares, divididos por áreas, como: política, social, econômica, jurídica, tendo sido adotado na Europa dentre outras, pela Faculdade de Direito de Coimbra.

A verdade é que urge essa integração: não se pode pensar, no mundo presente, a nosso ver, em ensino puramente jurídico. Há que se dividir o estudo em campos de ação e, em cada qual, ministrar ao aluno noções de ciências afins, conforme as áreas que escolher, habilitando-o a contribuir mias eficazmente para a sociedade em que vive.

A ação do advogado não se perfaz - hoje, com mais clareza, definida com o simples exercício de habilitações jurídicas e com conhecimentos apenas da ciência do Direito. Ao advogado de empresa são exigidos, por exemplo, conhecimentos de administração, contabilidade, de economia, de finanças, de computação; ao de empresa pública, conhecimentos de administração, de política, de economia, assim por diante.

Dessa forma, consoante as áreas principais, a jurídica, a política, a econômica e a social, o curso do Direito poderia ser, a nível complementar, integrado por matérias de interesse precípuo, a ser ministradas por professores que, a par de sua titulação, tiverem vivência no setor. 


\section{A estruturação curricular vigente e a posição de nossa Faculdade.}

\subsection{A estruturaçäo curricular vigente nas Faculdades de Direito do país.}

Passando-se ao debate sobre a esquematizaçāo curricular em sī, temos a assinalar, de início, que, nesse ponto, se acham as Faculdades de Direito presas à tradição, detendo-se sobre disposição eminentemente jurídica, na linha básica da evolução do ensino superior nesse campo.

As matérias são distribuídas em ciclos, incluindo-se as consideradas básicas no primeiro ano do curso, prevendo-se depois as definidas como especiais, para, por fim, nos últimos semestres, estudar-se as denominadas "complementares" ("ciclo de especializaçāo" ou do "conhecimento específico"), em esquematização que obedece, normalmente, à conjugação dos fatores expostos.

Quanto à orientação do ensino, sentido prático pode ser notado em várias unidades, inclusive com a criação e a manutenção de atividades extra-curriculares, tais como cursos de estágio, de extensão, de aperfeiçoamento, inclusive por meio de entidades ligadas, poucas, no entanto, com o espírito de integração à realidade fática.

Complementa o quadro de disciplinas, em algumas Faculdades, a idéia da distribuição entre obrigatórias e facultativas ou opcionais, estas geralmente oferecidas a nível de complementação ou de especialização de conhecimento.

Com base nos modelos que, pessoalmente ou por pesquisa, pudemos analisar - a saber, algumas instituições européias e norte americanas e várias brasileiras - temos a anotar, em síntese, que, das orientaçōes prosperantes atualmente, a tendência geral é a de conjugação entre teoria e prática (a maioria) e, com respeito à constituição do currículo, predomínio quase exclusivo de disciplinas, de cunho jurídico (no Brasil, quase absoluto).

Significativa reformulação imprimiu, a esse respeito, em 1975, a Faculdade de Direito de Coimbra ao que denominou "ciclo complementar" (entre nós, de "especializaçāo), dividindo-o em áreas de estudo, à escolha do interessado; em consonância com sua vocaçāo, a saber: "ciências jurídicas", "ciências jurídico-econômicas" e "ciências jurídico-políticas". com um elenco de disciplinas distribuido em: "núcleo obrigatório", "opçāo específica" e "opçāo comum" (dentre os quais se contam: direito comparado; direito europeu; sociologia do Direito, economia financeira e outras integrativas).

A fórmula, compreendida dentro do espírito de integração do jurista à realidade, permite o direcionamento do estudante a área de atuaçāo de sua escolha e as disciplinas inseridas em cada grupo proporcionam-Ihe, a par da espe- 
cificidade, visão globatizante da ciência jurídica e da situação do Direito em seu país e no contexto da Europa.

No Brasil os cursos jurídicos nasceram e floresceram à luz da cultura européia, traduzindo-se, desde o início, em preocupações de ordem teórico-práticas, mas recentemente vem evoluindo para uma postura profissionalizante.

Assim, mais presentemente é que vem sendo utilizada a técnica da distribuição em ciclos, com matérias de especialização como complementares.

Algumas Faculdades nāo fazem a distribuição por ciclos; algumas mantem ciclo básico comum a várias Faculdades; outras não contam com o ciclo complementar.

Mas, de um modo geral, apartadas algumas posições próprias, as matérias são eleitas e seriadas em consonância com o espírito inicial, ou seja, constituindo-se os dois primeiros anos em básicos para a formação do aluno, seguindo-se depois as matérias mais específicas, sempre na área estritamente jurídica.

Predomina, outrossim, por força da legislação vigente, a noção de currículo mínimo, com um feixe de disciplinas obrigatórias para o curso, aliás, generalizada no nosso ensino superior.

\subsection{A concepção curricular original e a evolução de nossa Faculdade.}

A estruturação curricular descrita prende-se à criação dos cursos superiores no país - e, portanto, à origem de nossa Faculdade - cuja vida, aliás, se confunde com a própria história da Faculdade de São Francisco, a primeira das instituições do gênero.

De fato, a criação dos cursos jurídicos, entre nós, foi realizada, conforme nos mostram os estatutos do VISCONDE DE CACHOEIRA, com "matérias que podem formar um jurisconsulto brasileiro", cujo conteúdo e alcance são explicados, minuciosamente no referido documento (Capítulo III das explicações do Estatuto) (in "o Poder Legislativo e a criaçāo dos cursos jurídicos" editado pela Subsecretaria de Edições Técnicas do Senado, Brasília, 1977, p. 332).

O curso foi distribuido por cinco anos, estudando-se, nos dois primeiros, os princípios gerais e universais, que informam todos os ramos do Direito, como matérias elementares; no terceiro e no quarto, a legislação pátria e a geral e, por fim, no quinto ano, suas aplicaçōes, voltadas para a preparação do bacharel para atuação no foro, enfatizando-se então as análises de textos e de jurisprudência e a realização de composições pelos estudantes. 
O encadeamento do curso obedeceu à fórmula de ministração progressiva de matéria, a partir dos princípios mais gerais, passando-se pelo direito posto, até alcançar-se as aplicações práticas (art. 10 da lei de 11.8.1927, que instituiu os dois primeiros cursos jurídicos do país, em S. Paulo e em Olinda), obtendo o candidato, no final, o título de bacharel (art. 9\%), sendo de realçar-se outrossim que a remuneração dos lentes correspondia à dos desembargardores (art. 39).

A iniciativà pertenceu ao Visconde de São Leopoldo, José Feliciano Fernandes Pinheiro, que ofereceu indicação, datada de 12 e apresentada a 14.6.1823 à Assembléia Constituinte, preocupado que estava o seu autor com "a difusāo das luzes e o adiantamento da instruçāo pública", "verdadeiras bases do governo constitucional". (o. cit., pp. 15 e 16).

Aliás, a educação da juventude era uma das preocupações básicas da Constituinte, manifestada já nas Províncias, face às dificuldades e vicissitudes enfrentadas pelos estudantes que tinham de atravessar o Atlântico para obter formação superior.

Propunha o autor, de início, a imediata criação, em São Paulo de uma "Faculdade de Direito Civil", unidade primeira da Universidade, sugerindo que a multiplicidade de cadeiras de Direito Romano fosse substituida por duas, uma de Direito Público Constitucional e outra de Economia Política, preocupado que estava com a integração do ensino jurídico à realidade de então.

Com as modificaçōes posteriores, a idéia vingou e a 1.3.1928 foi instalado no Convento de S. Francisco, sala no 2, o curso de Direito de São Paulo, tendo sido adotado para regê-lo estatuto calcado no de Coimbra, com as adaptações necessárias (o. cit., pp. 349 e 327, respect.).

Expandiu-se rapidamente e, desde o início, contou com a participação de figuras ilustres da vida de São Paulo, exercendo sempre influência sobre a sociedade.

De tal sorte tem sido essa interação que, no contexto geral do ensino jurídico no país, situa-se em posição singular a nossa Faculdade de Direito da Universidade de São Paulo que, a par de ser a primeira escola superior de Direito do país, antecedeu à própria instituição da Universidade como tal.

Moldada no referido convento (Colégio de São Paulo, cujo estatuto foi aprovado em 11.6.1776), a Faculdade de Direito de tal modo se integrou à vida social, política, jurídica e econômica de São Paulo, que com a cidade se identifica, naquilo que de mais expressivo na alma bandeirante se contem.

E mais: de sua ação na formação de inúmeras gerações de juristas, viu seu nome, graças a participação em movimentos importantes da vida nacional, es- 
tender-se a níveis nacionais e internacionais, ocupando ora, seguramente, posição de relevo dentre as mais importantes instituições mundiais do ensino superior.

Assim, vem merecendo candentes e brilhantes manifestações de diferentes pensadores, uníssonos na loa merecida a tão tradicional e atuante entidade, cujos serviços prestados à nação são incontáveis.

\subsection{Singularidade de sua posição no contexto das demais Faculdades.}

Com efeito, a singularidade de sua atuação pode-se notar no extraordinário fascínio que sempre exerceu sobre a comunidade, como, evocando cronistas de époas áureas lembra CARLOS PENTTEADO DE REZENDE, nos planos social, econômico e intelectual de nossa terra por suas "fecundas tradiçōes" e "prestígio sempre atuante", congregando, ao longo do tempos, os seus nomes mais ilustres. ("Algumas páginas sobre a velha Academia de Direito de São Paulo", in "Revista da Faculdade de Direito", 1977, 1 fase, v. LXXII, p. 70).

Bafejada pelas três deusas a que se refere seu historiador SPENCER VAMPRÉ - a Poesia, a Eloquência e a Saudade - extrapola, em sua atuação, à simples formação de bacharéis em Direito, contribuindo também, como lembra WASHINGTON DE BARROS MONTEIRO, na preparação dentre outros, de estadistas, políticos, oradores, professores e magistrados, que tem "exercido influência nos destinos da nacionalidade" ("Sesquicentenário da Faculdade de Direito", in "Problemas Brasileiros", 1977, no 166, p. 5).

Por isso é que ALFREDO BUZAID realça que sua missão "não é simplesmente a de formar profissionais para o exercício da advocacia", pois, "numa sucessāo nunca interrompida, esta Faculdade traça os destinos da Pátria na obra de seus filhos", sendo verdadeiro "espírito que ilumina a vida nacional no foro, na política, na tribuna, no jornalismo, nas letras". E, em um arroubo, conclui: "Se tocasse a esta casa o papel de formar bacháreis em Direito, seria um curso profissional. Se o ensino se limitasse à sistematizaçāo dos princípios e à hermenêutica dos preceitos legais teria validade científica, mas the minguaria calor humano, a perspectiva dos largos horizontes, a paisagem das construçōes imortais. Seria uma escola, nāo um templo. Teria professores, não sacerdotes. Viveria em contato com os códigos e as leis, mas estaria divorciada do mundo, dos seus dramas, das suas crises, das idéias que o agitam." ("A missāo da Faculdade de Direito na conjuntura política atual", in "Revista da Faculdade de Direito, 1968, v. LXIII, p. 74).

No mesmo diapasão e depois de salientar que de suas cadeiras sairam estadistas, políticos, empresários e outros elementos, acentua MIGUEL REALE o "que os une é o "sentimento da consecução humana", pois o Direito é "empe- 
nho global da vida..." é "a vida mesma em todas as suas expressōes, na medida em que todos devem se submeter às exigências éticas de umar convivência ordenada". ("A Faculdade de Direito na cultura brasileira", in "Revista da Faculdade de Direito, 1976, v. LXXI, pp. 231 e 233).

A influência da Faculdade na vida da nação levou, por sua vez, PHILOMENO JOAQUIM DA COSTA a considerá-la "patrimônio sedimentado das galas do mais puro e indobrável brasileirismo". ("A instalação dos cursos de pós-graduaçāo a Onze de Agosto", in "Revista da Faculdade de Direito", 1972, LXVII, p. 350).

Acresce-se a essas a manifestação de MARIO HOEPNNER DUTRA no sentido de que "nāo houve movimento nacional que nāo tivesse encontrado no abrigo de seus muros a veemência da palavra a brandir na causa e, sobretudo, na açäo", pois a Faculdade "guarda em si toda a socialidade histórica de nossa terra" (discurso proferido nas Comemoraçōes do sesquicentenário", in "Altar de Glória", SP., Lex Editora, 1977, p. 12).

Por isso é que JOSÉ PINTO ANTUNES assinalava, quando da cerimônia de lançamento da pedra fundamental do novo prédio no campus da USP, que a História do Brasil a "Academia do Largo de Sāo Francisco vem fazendo há perto de século e meio". ("A pedra fundamental da nova Faculdade de Direito na Cidade Universitária", in "Revista da Faculdade de Direito", 1973, v. LXVIII, 2a fase, p. 404), aspecto esse realçado também por GENTIL DO CARMO PINTO com as seguintes palavras: "Centúria e meia de fatos e tradiçōes ressoam de teu solo sacrossanto, trincheira da consciência jurídica, cidadela de idealismo e cultura, vanguarda de aspiraçóes liberais, baluarte de patriotismo" ("Discurso em comemoraçāo do sesquicentenário da fundaçāo dos cursos jurídicos", in "Revista da Faculdade de Direito", v. LXXII, 1977, 2" fase, p. 403).

Atesta a sua presença marcante em movimentos nacionais a célebre manifestação pelo Estado de Direito, com a leitura, em 1977, da "Carta aos Brasileiros", em que GOFFREDO TELLES JR. realçou a sua fidelidade às tradições de nossa terra, "indefectível e operante, que escreveu as Páginas da Libendade, na História do Brasil" ("Carta aos Brasileiros", inserida na citada Revista, p. 412).

Essa chama que pulsa na Faculdade inspirou, ainda, PAULO BONILHA a proclamar: "Este chāo ainda produz a seiva da terra bandeirante, que alimentou as passadas geragōes de mestres e estudantes, nutre as presentes e há de sustentar as futuras, até quando houver, sobre a Terra, sede e fome de Justiça", (discurso, na mesma ocasião proferido, incluido na mesma Revista, p. 406). 


\subsection{Problemas enfrentados pela Faculdade e propostas para o seu equacionamento.}

Com tão vibrantes manifestações - a que se somam inúmeras outras sente, mesmo o mais cético dos analistas, que, de um lado, por sua singularidade, nossa Faculdade não pode ser examinada no contexto geral das entidades de ensino superior no país e, de outro, difícil se torna o diagnóstico da sua posição frente ao momento atual.

Não se pode dizer, de início, que se trata de instituição em crise, até por que segue normalmente em sua trilha de formação de pessoal habilitado para o exercío de funçōes próprias da carreira jurídica, distinguindo-se ademais pela obra de seus filhos em diferentes setores da vida nacional.

Mas sofre, sem dúvida, face à inserção no contexto da Universidade, os problemas já apontados, em especial, os de insuficiência de verbas, que tolhe atividades de pesquisas; impede a concessão de bolsas de estudos; e de inadequação da política de remuneração de seus colaboradores, que desestimula o ingresso e a manutenção na atividade docente, dificultando, assim, o acolhimento de estudiosos e de especialistas que são atraídos pela iniciativa privada, ou pelo serviço público, impedindo-se, assim a sua integração, ao respectivo quadro, até para atender aos cursos normais.

Essas questões tem sido postas nos congresos internos da Faculdade prática, aliás; adotada, há algum tempo, em nossas Universidades, para uma auto-avaliação periódica - a par de outros, em especial de caráter metodológico e curricular, que vem atormentando os espíritos preocupados com a situação atual do ensino jurídico.

Medidas urgentes devem, a próposito, ser tomadas, imprimindo-se novas dimensōes à Faculdade, dignas de sua tradição e de sua grandeza.

Sanadas as deficiências gerais apontadas, e mais, simplificada a estrutura administrativa e disciplinada mais realísticamente a carreira docente, poderia a Faculdade - assim como as demais unidades da instituiçāo (algumas, aliás, já bem atuantes nesse sentido) - ampliar o elenco de serviços prestados à comunidade, inclusive internamente, colaborando mais decisivamente para o progresso geral do país, a fim de nāo estreitar a sua atividade à de transmissão de conhecimentos.

Com efeito, aparelhada sob essa nova visão, poderia pensar-se em: criar Institutos e centros de pesquisas nos diferentes Departamentos para a realização de trabalhos remunerados de interesse para a comunidade, inclusive com a participaçāo de alunos; realizar mais cursos de extensāo e de aperfeiçoamento, em função a demanda do mercado; pôr em prática estágios profissionalmente 
orientados nas áreas de interesse do mercado; instituir prêmios e concursos internos para os alunos do bacharelado; conceder bolsas de estudos a alunos interessados; promover, sistematicamente, intercâmbio cultural e de serviços com outras instituições nacionais e internacionais, e, mesmo órgãos governamentais; manter convênios com empresas para estágios e para prestação de serviços e outras atividades compatíveis com seus objetivos.

Sugerimos, pois, sejam tais pontos estudados e, com brevidade, instituidos os programas possíveis, que muito contribuirão para os fins expostos.

Observa-se, pois, que muito poderia, ainda, a Faculdade fazer em prol da comunidade, seja interna, seja externamente, daí porque o diagnóstico de sua posição - que sofre os reflexos, em especial, do defasado sistema de remuneração do corpo docente - no momento não nos oferece, dentro do espírito citado, uma visão alentadora.

Acresce anotar, ainda, que interessantes seriam: a instituição de programa de preparação e de orientação do corpo docente, quanto aos novos objetivos; mecanismos de integração dos alunos às novas tarefas; reexame dos atuais programas das disciplinas, com ligação entre si e ajustamento às necessidades atuais; e adoção de metodologia coerente com as novas realidades do país.

Isso significa que, em nosso entender, também na Faculdade de Direito da USP, não é apenas curricular o problema. Vale dizer: não se resume a revisão de currículo qualquer proposta tendente a dela extrair postura mais positiva para a eliminação da decantada crise do ensino jurídico. Há que se preparar, devidamente, para a assunção de nova posição sugerida.

Isso inobstante, também com respeito à disposição curricular, aperfeiçoamentos poderiam ser introduzidos, a fìm de ajustá-la à já mencionada orientação realística, como adiante apontaremos.

\subsection{Orientaçāo atual do ensino jurídico: a posiçāo do currículo da nossa Faculdade.}

Com efeito, passando ao ensino propriamente dito, temos a anotar, de início que, durante largo tempo e inobstante a sempre presente atuação da Faculdade, prosperou em seu contexto uma orientação teórica, distribuindo-se e ensinando-se as matérias com espírito puramente intelectual, constando que, em 1908 , na Bahia, se fez ouvir a primeira voz que, legislativamente, propunha reforma no ensino superior tendente a imprimir cunho prático aos cursos de $\mathrm{Di}$ reito. 
Destacavam-se então as lições altamente eruditas e grandes dotes de oratória dos mestres, que, aliás, deliciaram a juventude estudante por muitas. e muitas gerações!...

A persistência de cursos teóricos e de preleção dịscursivas levou, mais tarde, a par de outras manifestações, o Congresso de Ensino Jurídico de 1927 a preconizar modificações que viessem a ajustá-lo às necessidades da vida profissional.

Com a criação da Universidade de São Paulo (Dec. 6.283, de 25.1.1934), foi traçada a filosofia que deveria nortear a vida acadêmica entre nós, destacando-se em seu conteúdo, a ênfase para desevolvimento do espírito de iniciativa, de trabalho e de pesquisa, ideais esses que também inspiraram o seu Regimento Geral (Dec. 52.906, de 27.3.62).

Esses mesmos pontos serviram de base para a definição, a nível nacional, de política específica para o setor, plasmada depois da denominada "Lei de Diretrizes e Bases da Educação Nacional" (Lei 4.024, de 20.12.61), onde se declarou por expresso que são "objeto do ensino superior a pesquisa, o desenvolvimento da ciência, letras e artes e a formação de profissionais de nível universitário" (art. 66) (reproduzido pela Lei 5.540, de 28.11.68, art. 29) (interessantes são a propósito da reforma: o trabalho de KEITH S. ROSENN, de 1969, denominado "The reform of legal education in Brazil", in "Journal of Legal Education", v. 21, no 3, p. 251 e segs.; e o de DORIVAL TEIXEIRA VIEIRA, "A reforma do ensino superior", in "Problemas Brasileiros", 1973, n 114, p. 3 e segs.).

Nesse contexto vem assumindo importante papel o Conselho Federal de Educação, órgão que cuida da referida política, definindo, por meio de Resoluções, orientações e critérios que vem disciplinando os cursos superiores no país.

Em função da orientação que vem fixando, o sistema atual de ensino superior encontra-se, em suas linhas gerais, estruturando em consonância com normas que, na linhia tradicional, refletem a preocupação precípua de formação, mesclada a certa profissionalização, em função da diretriz imposta pela reforma.

O curso deve dividir-se em semestres, lastreado no mecanismo de créditos, sendo distribuido em ciclos, a saber: o básico, "destinado a formação cultural (dois semestres) e o institucional, composto de matérias obrigatórias, com disciplinas básicas e profissionais, e algumas opcionais (seis semestres) e, por fim, o ciclo de especialização, ou de conhecimento específico (ultimo ano do curso) (Resolução 03, de 26.2.72). 
Abraçou-se, assim, oficialmente, a referida orientação teórico-prática, prendendo-se os ciclos à preparação do aluno (formação) nos primeiros semestres, para, nos últimos anos ministrar-lhe conhecimentos específicos e profissionalizantes (informação) nas áreas eleitas.

Ora, esse esquema foi implantado em nossa Faculdade, passando, portanto, a influenciar o respectivo ensino que, paulatinamente, se foi afastando do teoricismo dominante, conjugando-se teoria e prática em sua esquematização e, mesmo, em sua ministração.

Mas, de outro lado, tem predominado, na configuração curricular, disciplinas eminentemente jurídicas, com algumas poucas exceções, apresentandose, portanto, cunhado de forte sentido técnico, dentro da diretriz apontada.

\subsection{Críticas ao sistema e a busca de novas fórmular curriculares.}

Discorrendo sobre a reforma e com vistas ao currículo da Faculdade, explicava OSCAR BARRETO FILHO que a par de matérias "que visam precipuamente à formaçāo profissional do advogado, sāo previstas algumas matérias básicas, de caráter geral, que tem por objetivo preparar o bacharel para a sua missão e melhor integrá-lo na comunidade", além de "matérias práticas para completar o curriculo".

E, depois de enuciar as disciplinas inseridas, manifesta a sua concordância com a especialização, lembrando que áreas especializadas, com opções para escolha do aluno, já existiam nos Estados Unidos da América do Norte ("Plano de reforma do currículo do Curso de Graduaçāo em Direito", in "Revista da Faculdade de Direito", 1972, v. LXVII pp. 117, 118, 120 e 121).

Mas, como em outros países, os resultados deste sistema, entre nós, tem sido muito discutidos, existindo inúmeras vozes destoantes, a ponto de ecoar essa insatisfação no seio do citado Conselho, que desenvolveu, a par de outras entidades, amplos estudos a respeito.

Assim, após o parecer 614/80, em que se constatou como se encontrava o ensino do Direito no país, foi aprovada, em seu interior, proposta de reformulação, tendo, para tanto, sido nomeada Comissão de especialistas.

De seu trabalho resultou um anteprojeto, oferecido em 1982, para debate nacional, prevendo-se nova "grade curricular", com disciplinas eletivas e a criação de "laboratório jurídico" nas Faculdades. As matérias foram divididas em: obrigatórias de formaçáo básica e de formação geral, para os primeiros semestres, seguindo-se as de formação profissional e, por fim, as de habilitações específicas (por áreas, para os últimos semestres). 
Críticas gerais - inclusive quanto a improcedência terminológica e a inadequação à realidade - mostraram logo a impropriedade da nova concepção, que acabou por não prosperar.

Persiste, pois, o modelo enunciado, abraçado pelas Universidades oficiais e por inúmeras instituições privadas, dẹtre as quais algumas ainda se acham submetidas à simples seriação.

Dessa forma, em termos gerais, nossa Faculdade se encontra integrada ao modelo oficial.

De fato, examinando-śe o seu currículo, constata-se que, efetivamente, se ajusta ao esquema tradicional, assumindo, em sua diagramaçāo, a divisāo do curso em ciclos básico e institucional (oito semestres), e de especialização (dois semestres).

Assim é que, com a introdução do sistema de divisão em ciclos, a seriação que sempre obedeceu à ordem inversa do grau de generalização - perfez-se apenas nos cursos básico e institucional, distribuindo-se, outrossim, o ciclo de especialização em áreas, a saber: "Direito Público, Administrativo e Financeiro; Direito Penal e Criminologia; Direito Privado e Processo Civil; Direito de Empresas; Direito de Trabalho e da Segurança Social, com disciplinas obrigatórias e optativas (estas de maior especificidade ainda).

Outrossim, como se observa do exame das matérias existentes, apartadas as disciplinas básicas inseridas nos dois primeiros semestres, povoam o curso da Faculdade apenas matérias jurídicas, orientaçāo que prevalece no de especialização, com poucas exceções.

Vale dizer: a estruturação adotada na Faculdade é, em sua filosofia e em sua diagramação, a da reformá citada.

Mas, preocupada com o aperfeiçoamento do curso e depois de reflexões sobre a experiência obtida com a realização, a nível de pós-graduação, do curso de especialização, decidiu a Congregação da Faculdade, em sessão de 5.6.85, alterar o "ciclo de especializaçāo" do bacharelado (semestres IX e X), com fulcro em proposta oferecida pela Comissão encarregada de estudar o assunto.

Fixou-se, como principal diretriz, a de nāo mais se conceber como de especializaçāo o último ciclo do curso de bacharelado, ficando aquela reservada para o programa de pós-graduação; com isso, passou o citado ciclo a denominar-se "complementar", definindo-se como "fase de flexibilização do ensino", os dois últimos semestres do ciclo profissional. Em consequência, conferiu-se ao aluno liberdade total de escolha das disciplinas até completar-se o número de créditos necessários, respeitadas as condicionantes dẹ horário e de espaço da 
Faculdade e ressalvada ao interessado a possibilidade da obtençāo de habilitação específica nas áreas então existentes.

Observa-se, pois, quanto ao ponto principal da reformulação - que está sendo aplicada - que o último ciclo, agora com a denominação coimbrã, não mais se compõe de áreas, ficando a critério do interessado a escolha e a conjugação de disciplinas dentro do leque oferecido pela Faculdade, mantido, outrossim, à opção do interessado, o esquema oficial de habilitação.

Entendeu-se, pois, frente a dificuldades verificadas na escolha, pelo aluno, dentro do sistema de definição de áreas, que, com a abertura, o interessado constituirá o próprio currículo, a exemplo do que ocorre no curso de pós-graduação, com a diferença de que, no último, existe prévia orientação dos professores credenciados que, no bacharelado, se tem por facultativa.

A experiência dirá melhor quanto aos resultados, mas, com a devida vênia, ainda se nos afigura necessária reformulação da própria concepção do ciclo em questão, à luz das premissas expostas.

\subsection{Sugestóes para o aperfeiçoamento de nosso currículo.}

De fato, aqueles que se encontram, como nós, em contato intímo com a Faculdade, sentem, ainda, a necessidade de ajustes no currículo, a fim de que se possam alcançar os objetivos retro-mencionados.

Nos debates e nas proposições do VI Congresso da FADUSP (de que também participamos e cujos resultados, foram publicados pelo jornal "Onze de Agosto", edição especial de novembro de 1985), ficou evidente que cumpre, de imediato, fazer-se revisão de conceitos e de fórmulas, no ensino jurídico, sentindo-se, quanto à questão curricular, a inevitável conclusão de que se deve buscar a adequação do curso de bacharelado à realidade de nossos dias, ainda em consonância com as finalidades enunciadas.

Maior participação ao aluno na Faculdade e sua integração às atividades da vida se constituem na tônica das proposiçōes oferecidas, que pautam por uma postura menos teórica na ministração do curso.

Além disso, cumpre anotar que Congressos outros - que, inclusive, no seio das entidades de classe, se realizaram - tem insistido, nesse pontos, com trabalhos de diferentes intelectuais preocupados com a crise presente, destacando-se, por sua objetividade, os de ADA PELLEGRINI GRINOVER e OSCAR BARRETO FILHO (cit.). 
Cabe-nos então indagar, frente à situação existente, se a estrutura curricular de nossa Faculdade atende às necessidades e aos objetivos enunciados, discutidos os modelos oficiais e a variante adotada pela D. Congregação.

Ora, inobstante estejam coerentes com a diretriz básica já debatida, a verdade é que comportam ambos certas modificações, que lhes conferirão melhor correspondência à realidade presente. Assim, permitímo-nos traçar algumas sugestōes que, aliadas às providências já referidas, farão com que o currículo de nossa Faculdade possa servir, com mais eficiência, às finalidades propostas.

Carecem eles, em nosso entender, do espírito integrador citado, residindo sua principal deficiência no ciclo complementar, que se nos afigura mais adequado, de um lado,com a divisão em áreas, mas não do Direito, e sim da realidade, a saber: política, econômica, social e jurídica, e, de outro, com a sujeição da escolha das áreas à orientação dos professores face à naturais dificuldades dos estudantes. Matérias de integração do estudo, como Política, Filosofia, Finanças e outros, deverão figurar no currículo complementar, distribuídas por setores correspondentes do Direito (D. Civil; D. Comercial; D. do Trabalho e outros).

Exemplificando: na área econômica, noçōes de Economia, Finanças, Direito Econômico, Direito Societário; Direito Tributário; Direito do Trabalho; na área jurídico-penal: Sociologia; Criminologia; na área política: Ciência Política; Direito do Estado; Direito da Administração; Relaçôes internacionais, dentre outras matérias, consoante estudo específico a ser desenvolvido.

Assinale-se, para efeito de elucidação, que em nada se confunde o referido ciclo com o de especialização oferecido em pós-graduação, este voltado a bacháreis e com programas de aprofundamento em áreas de estudos visado, tendentes a produção de trabalhos científicos.

Assim, defendemos, respeitadas as disposições regulamentares competentes: a permanência dos ciclos, inclusive o "complementar", este concebido como estudo crítico da realidade e voltado à profissionalização; a divisão deste em áreas, a saber: jurídica, econômica, social e política, conforme o campo de atuação preferido pelo interessado, prevendo-se sub-áreas, conforme as funções possíveis ao bacharel (diplomacia, administração pública ou privada; política, exercício da advocacia ou atividade afim), estabelecendo-se a esquematização de disciplinas compatíveis, obrigatórias e opcionais, conforme os setores do Direito (por exemplo, D. Civil, D. Comercial, D. do Trabalho, D. Tributário, D. Administrativo); a inserção de disciplinas integrativas no ciclo complementar (tais como: D. Comparado, Filosofia do Direito, Administração, Política, Econômia, Finanças, Computação, Contabilidade e outros, sempre em conexão 
com as necessidades reais do bacharel); e a escolha orientada das áreas e das disciplinas, ou seja, com a participação dos professores correspondentes.

Parece-nos, outrossim, que a estruturação dos ciclos básico e institucional atendem, de um modo geral, às diretrizes definidas, podendo fazer-se revisão tendente a verificar-se, em especial, se as disciplinas básicas se inserem dentro da filosofia exposta e a recompor-se, quando necessária, a distribuição de matérias, em caso de modificação do ciclo complementar.

Ajustes nos programas complementarão o quadro de providências que nos parecem pertinentes para a nova concepção.

Postura prática do professor e direcionamento dos alunos para pesquisas sobre fatos da vida real são elementos indispensáveis na orientação preconizada, dentro do espírito pioneiro que nesta casa, a partir de 1938, desenvolveu CESARINO JUNIOR.

Assim se poderá chegar à integração acenada, mantendo-se, então, em nossa Faculdade, de início, a preocupação básica de formação humanística e, depois o aguçamento do senso de profissionalização, mas sob diretriz integradora do estudante ao mundo exterior em que, como bacharel, atuará.

\section{BIBLIOGRAFIA}

ANTUNES, José Pinto: "A pedra fundamental da nova Faculdade de Direito na Cidade Universitária", in "A Revista da Faculdade de Direito", 1973, v. LXVIII, 2" fasc, p. 404.

ANTUNHA, Heládio Cesar Gonçalves: "A Universidade de São Paulo, 45 anos depois", in "O Estado de S.Paulo", de 28.1.79, p. 129.

BARRETO FILHO, Oscar: "Novos métodos do ensino do Dircito. A experiência norteamericana", in RF. 229/352. "Plano de reforma do currículo do Curso de Graduação em Direito", in "Revista da Faculdade de Direito", 1972, v. LXVII, p. 115 e segs.

BARROS JR., Cássio de Mesquita e TUCUNDUVA, Ruy Cardoso de Mello: "Estágio e formação profissional do advogado", SP, RT. 1980.

BERNARDO, Hugo Gueiros: "Sobre a metodologia do ensino jurídico", in "Revista de Informação Legislativa", 32/83.

BEVILAQUA, Clovis: "História da Faculdade de Direito de Recile", Rio, Francisco Alves, 1927.

BITTAR, Carlos Alberto: "Novas técnicas de comunicaçāo no âmbito universitário e seus reflexos na comunidade", in "Revista de Informaçāo Legislativa", 86/331.

BUZAID, Alfredo: "A missão da Faculdade de Direito na conjuntura política atual". in "Revista da Faculdade de Direito", 1968, v. LXIII, p. 71 e segs. 
CAETANO, Marcelo: “A reforma dos estudos jurídicos em Portugal”, in RF, 227/365.

CESARINO JR, ANTONIO FERREIRA: "O jurista na era tecnocrática", in "Revista da Faculdade de Direito", 1969, v. LXIV, ps. 189 e ss.

COSTA, Philomeno Joaquim da: "A instalação dos cursos de pós-graduação a Onze de Agosto", in "Revista da Faculdade de Direito", 1976, v. LXVII, p. 343 e segs.

DALLARI, Dalmo de Abreu: "As Arcadas na política brasileira", in "Suplemento Cultural" de "O Estado de S.Paulo", de 7.8.77, no 43, p. 6.

FACULDADE DE EDUCAÇÃO DA UNIVERSIDADE FEDERAL DO RIO GRANDE DO SUL: "Planejamento e organização do ensino", Porto Alegre, Editora Globo, 1975.

FALCĀO, Joaquim de Almeida: "O ensino jurídico e o currículo mínimo", in "Reforma do Ensino Jurídico", ("Cadernos da PUC/RJ, 1974, no 17, p. 97 e segs.).

FERRAZ JR., Térsio Sampaio: "Reforma do ensino Jurídico: reformar o currículo ou o modelo", in "Reforma do Ensino Jurídico", "“Cadernos da PUC/RJ, 1974, no 17, p. 126 e segs.").

FROSINI, Vittorio: "La Universidad desintegrada: la situación italiana", in "Anales de la Catedra Francisco Suarez". 198 /81. v. 20/21. p. 219 e segs.

GARRIDO. Manuel Jesus Garcia: "La universidade en la reforma educativa española", in "Revista da Faculdade de Direito". 1974, v. LXIX, fasc. 2, p. 193 e segs.

GATI. Jacqueline e GLETZAL, Jean Jacques: "La enseñanza del derecho y la formación de las capas dirigentes en Francia", in "Anales de la Catedra Francisco Suarez, 1980/81, v. 20/21. p. 159 e segs.

GRINOVER, Ada Pellegrini: "O advogado e a formação jurídica", in "Revista da Faculdade de Direito", 1978, v LXXIII, p. 103 e segs.

GUIMARĀES. Moacyr Expedito Vaz M.: "Universidade e comunidade: integração inadiável", in "Problemas brasileiros", 1980, n" 193, p. 4 e segs.

HUNSAKER. DAVID M.: "Law, humanism and communication; suggestions for limited curriculum reform". in "Journal of Legal Education", 1980, v. 30, p. 417 e segs.

L.EX EDITORA: "Altar da glória" (Homenagem ao sesquicentenário da fundação dos cursos jurídicos no Brasil). SP 1977.

MACDONAL.D. RODERICK A.: "Curricular development in the 1980s: a perspective", in "Journal of L.egal Education", 1982, n" 32, p. 571 e segs.

MEL . O Filho, Álvaro: "M ctodologia do ensino jurídico", Rio, Forense, 1979.

M()NBEig. Pierre: "Obra de clarividência e de paixão", in "O Estado de S. Paulo", de 28.1.79. p. 129.

MONTEIRO. Washington de Barros: "Sesquicentenário da Faculdade de Direito", in "Problemas Brasilciros". 1977, n" 166, p. 2 e segs. 
MONTORO, André Franco: "Objetivos e método do ensino do Direito", in "Revista de Informação Legislativa", 42/63 e "Revista da PUC", 1976 no 98, p. 3 e segs.

OLIVA, Waldyr Muniz: "A contribuição da USP à sociedade", in "O Estàdo de S. Paulo", de 28.1.79, p. 129.

PAUL, Wolf: "Formación del jurista entre teoria y praxis", in "Analises de la Catedra Francisco Suarez", 1980/81, v. 20/21, p. 115.

PORTO, L. de A. Nogueira: "A criação dos cursos jurídicos", in "Suplemento Cultural" de "O Estado de S. Paulo", de 7.8.77, no 43, p. 3.

RAMOS, José Nabantino: “O Ensino do Direito”, in RT 490/249.

REALE, Miguel: "A Faculdade de Direito de São Paulo na cultura brasileira", in "Revista da Faculdade de Direito", 1976, v. LXXI, p. 227 e segs. "A Faculdade de Direito e a história das idéias no Brasil", in "Suplemento Cultural" de "O Estado de S. Paulo", de 7.8 .77 , no 43 , p. 5 .

REZENDE, Carlos Penteado de: “Algumas páginas sobre a velha Academia de Direito de S. Paulo", in "Revista da Faculdade de Direito", 1977, 1 fasc., v. LXXII, p. 31 e segs.

ROSENN, Keith S.: "The reform of legal education in Brasil", in "Journal of Legal Education", 1969 , no 21, p. 251 e segs.

SUBSECRETARIA DE EDIÇÕES TÉCNICAS DO SENADO FEDERAL: “O Poder Legislativo e a criação dos cursos jurídicos”, Brasília, 1977.

TÁCITO, Caio: "O desafio do ensino do Direito", in RF 233/327.

TEIXEIRA, Sálvio de Figueiredo: “O ensino jurídico e o exercício profissional da advocacia nos Estados Unidos", in "Sciencia Jurídica", 1980, t. XXIX, p. 113 e segs.

UNIVERSIDADE DE SĀO PAULO: "Catálogo geral dos cursos de graduação", SP, ECA, 1976 e "Informações acadêmicas", SP, 1982.

VIEIRA, Dorival Teixeira: "A reforma do ensino superior", in "Problemas Brasileiros", 1973, no 114, p. 3 e segs. 